East African Medical Journal Vol. 80 No. 12 December 2003

DIPHTHERIA SEROPREVALENCE IN CHILDREN LIVING IN THE EASTERN TURKEY

S. Altinkaynak, V. Ertekin V., A. Arik, A. Guraksin. Ataturk University, Faculty of Medicine, Department of Paediatrics, University Faculty of Medicine,

Department of Public Health, Guraksin, A., Ataturk University Faculty of Medicine, Department of Pediatrics, Erzurum, Turkey

Request for reprints to: Dr. V. Ertekin, Ataturk University, Department of Pediatrics, Faculty of Medicine, 25200-Erzurum, Turkey

\title{
DIPHTHERIA SEROPREVALENCE IN CHILDREN LIVING IN THE EASTERN TURKEY
}

\author{
S. ALTINKAYNAK, V. ERTEKIN, A. ARIK and A. GURAKSIN
}

\begin{abstract}
Objectives: To determine the seroprevalence of diphtheria in 767 children aged 0-6 years and to identify the relationship between diphtheria seroprevalence and several sociodemographic characteristics of the study subjects in the Erzurum, Erzincan and Kars cities situated in Eastern Turkey.

Design: A cross sectional study.

Setting: The subjects were recruited from three cities (Erzurum, Erzincan, Kars). The sampling method of 30 clusters recommended for field studies was used for a predetermined number of selecting subjects in the rural and urban areas in each city. Subjects: Of the 767 children included in this study, 423 were from Erzurum, 187 from Kars and 157 from Erzincan. Diphtheria serology was used to examine the blood samples by ELISA method.

Results: Positive diphtheria seroprevalence was detected in $77.9 \%$ of 767 subjects in Eastern Turkey. Seroprevalence was $74.5 \%$ in children younger than one year of age, increased to $84 \%$ at the age of 3-4 years, and reduced to $80 \%$ at the age of 4-5 years and $69.8 \%$ at the age of 5-6 years. The seroprevalence rates were similar in sex and number of siblings. Seroprevalence of diphtheria increased with educational level of parents in the rural area.

Conclusion: Positive seroprevalence against diphtheria in eastern Turkey is disturbingly low.
\end{abstract}

\section{INTRODUCTION}

Since the introduction of the diphtheria vaccine in the 1940's and improvements in social conditions, the disease has become very rare in European countries in which mass immunisation campaigns have been carried out. The incidence reached an all-time low in 1980, when only 623 cases were reported for European region of World Health Organization (WHO). At that time, the elimination of diphtheria in the European region seemed imminent, and the WHO Regional Committee for Europe endorsed the target of eliminating indigenous cases by the year 2000(1). However, in 1993 a striking resurgence of epidemic diphtheria in the Newly Independent States (NIS) of former Soviet Union draw attention to our lack of a full understanding of the epidemiology of the disease.

An analysis of this epidemic revealed that the reemergence of diphtheria in Russia, where the disease had been under control, was made possible by the presence of a very high percentage of unvaccinated or improperly vaccinated children(2-4). This situation favoured the spread of toxigenic strains introduced from areas in which the disease was endemic.

The European Advisory Group (EAG) on the WHO Expanded Programme on Immunization (EPI) coordinated the international and national efforts to control the diphtheria epidemic and recommended strategies for non-epidemic countries to inhibit the expansion of the disease. All countries should consider seroprevalence studies to assess the prevalence of diphtheria in their population(5).

Therefore, we conducted a study in order to determine the seroprevalence of diphtheria in the population aged 0-6 years and identify the relationship between diphtheria seroprevalence and several characteristics of the study subjects.

\section{MATERIALS AND METHODS}

In the present study seroprevalence of diphtheria was conducted in Eastern Turkey. The study sample consisted of 840 children aged 0-6 years in three cities (Erzurum, Erzincan and Kars). It was performed between July 2000 and April 2001.

The sampling method of 30 clusters was used for selecting subjects of a predetermined number in the rural and urban areas in each city. This is a practical method recommended by World Health Organisation for field studies(68 ). For this purpose, a total of 60 clusters in the rural ( 30 clusters) and urban (30 clusters) areas were determined. Therefore, it was planned that a total of 840 subjects including 463 subjects from Erzurum, 205 subjects from Kars and 172 subjects from Erzincan be included in the study. These numbers were distributed among 0-6 years of age population of each city proportional to actual size. The age groups were 
separated into one year groups. According to the socioeconomic levels of the families, children were classified into three groups; high, moderate or low socio-economic level group. Composite index was used to determine the socioeconomic level of the families(9).

When the investigators reached the cluster, the door number to start was chosen randomly houses were visited after reading the predetermined number in each age group. Each potential subject who was interviewed and who agreed to participate read and signed a written informed consent form. A questionnaire about several characteristics of subjects was used to obtain data, on diphtheria epidemiology. Informed consent was obtained from all parents of the children and a pediatrician examined the subjects. Following the interviews, appropriate blood samples were taken from subjects for seroprevalence. Twenty-six selected subjects (3\%) could not be reached, parents of 24 children (2.9\%) did not accept to participate in the study and blood samples of 23 children $(2.7 \%)$ could not be obtained. Therefore, the data in this study were obtained from $767(91.3 \%)$ children.

Blood samples were taken aseptically by venopuncture. The serum was separated by centrifugation and frozen at $20^{\circ} \mathrm{C}$ until the test was performed. Serum analyses were performed at the Microbiology Laboratory of Ataturk University Faculty of Medicine. Diphtheria antitoxin concentration was measured by enzyme-linked immunosorbent assay (ELISA) tests. For each serum sample, diphtheria antitoxin was performed using Virotech kits (10). Subjects whose antitoxin levels were below $0.01 \mathrm{lU} / \mathrm{ml}$ were classified as seronegative and those with an antitoxin level higher than or equal to $0.01 \mathrm{lU} / \mathrm{ml}$ as seropositive. As this was a descriptive study only percentages were calculated and no further statistical analysis was made

\section{RESULTS}

This seroprevalence study included a total of 840 subjects representative of the population aged 0-6 years in Eastern Turkey. The distribution of subjects who were selected for sampling, were interviewed and who underwent blood sampling in Eastern Turkey (Erzurum, Erzincan and Kars) is presented in Table 1. Seroprevalence could not be determined in $8.7 \%$ of sampled subjects and $6 \%$ of interviewed subjects. The socio-demographic characteristics of subjects are seen in Table 2. Of all population in the study, $53.2 \%$ were boys and $46.8 \%$ girls. Seventy seven of all children had three or fewer siblings and $32.3 \%$ had four or more siblings. Of mothers, $22 \%$ were illiterare, $60.1 \%$ had graduated from primary school, $16.4 \%$ from secondary or high school/college and 1,4\% from university. According to the educational level of fathers, $7.7 \%$ were illiterare, $36.8 \%$ had graduated from primary school, $45.8 \%$ from secondary or high school/college and $9.8 \%$ of them had graduated from university. Of families, while $25.3 \%$ had high socioeconomic status, $66.6 \%$ had moderate and $8.1 \%$ had low socio-economic level. Of subjects, $35.7 \%$ were living in urban areas, $44.7 \%$ in suburban area and $19.6 \%$ in rural areas.

Table 1

Distribution of subjects selected for sampling, interviewed and underwent blood sampling in three cities

\begin{tabular}{|c|c|c|c|c|c|c|}
\hline City & $\begin{array}{l}\text { No. of } \\
\text { sampled } \\
\text { subjects }\end{array}$ & $\begin{array}{l}\text { Interviewed } \\
\text { subjects** } \\
\text { No. }\end{array}$ & \multicolumn{3}{|c|}{$\begin{array}{l}* \text { Subjects undergoing } \\
\text { blood analysis }\end{array}$} & $\begin{array}{l}\text { Positive } \\
\text { seroprevalence } \\
\quad \%\end{array}$ \\
\hline Erzurum & 463 & 427 & 92.2 & 423 & 99.1 & 77.7 \\
\hline Erzincan & 172 & 167 & 97.1 & 157 & 94 & 78.1 \\
\hline Kars & 205 & 196 & 95.6 & 187 & 95.4 & 78.1 \\
\hline Total & 840 & 790 & 94 & 767 & 97.1 & 77.9 \\
\hline
\end{tabular}

* Percentages calculated for the number of sampled subjects in each city

** Percentages calculated for the number of interviewed subjects in each city 
Table 2

Several socio-demographic characteristics of subjects participating in diphtheria seroprevalence study

\begin{tabular}{|c|c|c|}
\hline $\begin{array}{l}\text { Characteristic } \\
\text { Age (years) }\end{array}$ & No. & $\%$ \\
\hline & 204 & 26.6 \\
\hline $1-2$ & 167 & 21.8 \\
\hline $2-3$ & 154 & 20.1 \\
\hline $3-4$ & 94 & 12.3 \\
\hline $4-5$ & 95 & 12.4 \\
\hline $5-6$ & 53 & 6.9 \\
\hline \multicolumn{3}{|l|}{ Sex } \\
\hline Boy & 408 & 53.2 \\
\hline Girl & 359 & 46.8 \\
\hline \multicolumn{3}{|l|}{ Sibling size } \\
\hline 0 & 132 & 17.2 \\
\hline 1 & 167 & 21.8 \\
\hline 3 & 118 & 15.4 \\
\hline 4 & 74 & 9.6 \\
\hline $5+$ & 56 & 7.3 \\
\hline \multicolumn{3}{|l|}{ Educational level of mothers } \\
\hline Illiterate & 169 & 22.0 \\
\hline Primary School & 461 & 60.1 \\
\hline Secondary-High S. & 126 & 16.4 \\
\hline University & 11 & 1.4 \\
\hline \multicolumn{3}{|l|}{ Educational level of fathers } \\
\hline Illiterate & 59 & 7,7 \\
\hline Primary School & 282 & 36.8 \\
\hline Secondary-High School & 351 & 45.8 \\
\hline University & 75 & 9.8 \\
\hline \multicolumn{3}{|l|}{ Socio-economic status } \\
\hline High & 194 & 25.3 \\
\hline Moderate & 511 & 66.6 \\
\hline Low & 62 & 8.1 \\
\hline \multicolumn{3}{|l|}{ Settlement Area } \\
\hline Urban & 274 & 35.7 \\
\hline Suburban & 343 & 44.7 \\
\hline Rural & 150 & 19.6 \\
\hline Total & 767 & 100 \\
\hline
\end{tabular}

Positive diphtheria seroprevalence was detected in $77.9 \%$ of 767 subjects aged 0-6 years in Eastern Turkey. Table 3 shows the distribution of diphtheria seroprevalence according to several socio-demographic characteristics. At the age of one year positive seroprevalence was $74.5 \%$, subsequently increased to $84 \%$ at the age of four years and then reduced to $80 \%$ at the age of five years and $69.8 \%$ at the age of six years. There were no differences, in seroprevalence rates between sexes and sibling sizes. Seroprevalence increased with educational level of mother and father. There was a highly significant difference in seroprevalence rates in respect to socio-economic status (Figure 1). Seroprevalence was found to be $79.2 \%$ in urban areas and $84.7 \%$ in rural areas.
Figure 1

The seroprevalence rates in respect to socio-economic levels of children

Table 3

Diphtheria seroprevalence for population aged 0-6 year by several socio demographic characteristics in three cities of Eastern Turkey

\begin{tabular}{lcc}
\hline Characteristic & No. & $\begin{array}{c}\text { Positive } \\
\text { seroprevalence (\%) }\end{array}$ \\
\hline
\end{tabular}

Age(years)

$<1$

$1-2$

$2-3$

3-4

4-5

5-6

Sex

Boy

Girl

Sibling Size

0
1
2
3
4
$5+$

$204 \quad 74.5$

$67-6$
154

$154 \quad 78.6$

$94 \quad 84.0$

$95 \quad 80.0$

$53 \quad 69.8$

$408 \quad 77.9$

$359 \quad 78.0$

$32-79.8$

$220 \quad 80.0$

$167 \quad 78.4$

$118 \quad 71.2$

$74 \quad 81.1$

$56 \quad 75.0$

Educational level of mothers

$\begin{array}{lll}\text { Illiterate } & 169 & 72.2\end{array}$

Primary School $\quad 461 \quad 80.7$

Secondary-High School $\quad 126 \quad 8.7$

$\begin{array}{lll}\text { University } & 11 & 81.8\end{array}$

Educational level of fathers
Illiterate

$\begin{array}{lll}\text { Primary School } & 282 & 79.4\end{array}$

Secondary High School $\quad 351 \quad 79.4$

$\begin{array}{lll}\text { University } & 75 & 78.7\end{array}$

Socio-economic status

$\begin{array}{lll}\text { High } & 194 & 77.3 \\ \text { Moderate } & 511 & 80.0 \\ \text { Low } & 62 & 62.9\end{array}$

Settlement Area

$\begin{array}{lll}\text { Urban } & 274 & 79.2\end{array}$

$\begin{array}{lll}\text { Suburban } & 343 & 84.7\end{array}$

$\begin{array}{lll}\text { Rural } & 150 & 84.7\end{array}$

\begin{tabular}{lll}
\hline Total & 767 & 77.9 \\
\hline
\end{tabular}




\section{DISCUSSION}

The marked decrease, and in some industrialized countries the virtual elimination of diphtheria over the last three decades is attributable to successful immunization programmes. However, even in those countries, diphtheria has reoccurred from time to time in more or less limited outbreaks, especially in areas where immunization coverage among children has fallen. In the early and mid-1980's an increased diphtheria incidence was reported from Sweden, the Federal republic of Germany (FRG), USSR, Turkey and Portugal (11). In the 1990's however, diphtheria has made a spectacular resurgence in the Newly Independent States of the former Soviet Union and several European countries (12-13). This situation favoured the spread of toxigenic strains introduced from areas in which the disease is endemic. Of the 170 cases reported from Turkey between 1990-1997, 70\% were from East and South-East Turkey. Most of the cases were at the age of 1-4 years(14). The epidemic raised many concerns about the levels of immunity to diphtheria in Western Europe, inciting many European countries to conduct seroprevalence studies, within the remit of European Union program.

The proportion of immune population against an infectious disease and it's epidemiologic characteristics are useful in planning control programmes and preventive measures. Therefore, the immunity of children included in the study was evaluated without taking the vaccination status into account. This is the percentage of children immunized against diphtheria. With the available tests it is not possible to separate the immunity due to immunization and natural infection from each other $(15,16)$. No history of diphtheria was obtained from $85 \%$ of the mothers and $15 \%$ could not give any information about this. In a recent study from Istanbul, $97 \%$ of the mothers of $0-9$ year old children reported that their children had not had diphtheria(17). The low percentage of mothers who could give history in our study may be due to the low education level of the mothers.

Of children included in our study, $77.9 \%$ were seropositive and $22.1 \%$ were seronegative. No correlation was seen between seropositivity and age groups. Many studies have reported that the antibody concentration after primary immunization decreases about $40 \%$ per year(15). The lowest percentage of seropositivity in our study was at the age of six $(69.8 \%)$. It was concluded that the second booster vaccine made at the first grade of primary school which was seven years old is suitable. The diphtheria seroprevalence were not different in boys, girls and sibling size. This result is similar with that of other studies (18-20). While there were no differences in seropositivity of children with high and moderate socio-economic levels (77.3\%-80\%), it was low in children with low socioeconomic levels $(62.9 \%)$. Similarly, two reports, one from Australia and another from the United States, indicated that Immunization rates and immunity levels were lower in children with low socio-economic levels(21,22). Seroprevalence of diphtheria increased with educational level of mothers and fathers the rural areas. These results of our study can be considered with a positive correlation between rates of diphtheria immunisation and the educational levels of parents and settlement area. In a study performed by Williams in 1995, higher immunization rates and immunity were reported in rural areas than in urban areas(23). Similar results were reported in the Turkish Demographic and Health Survey Report(24).

It is necessary to know the seroprevalence of any disease for an individual country in order to develop vaccination protocols and take appropriate preventive health care measures against diseases in different countries. Active immunization of susceptible groups remains the most important means of prevention. Our results show that the positive seroprevalence rate necessary for diphtheria elimination has not been reached yet in Eastern Turkey and this can cause diphtheria epidemics.

\section{REFERENCES}

1. World Health Organization: Operational targets for EPI disease, EUR/ICP/CMDS. 1996; 010114.

2. Galazka A.M., Robertson S.E., and Oblapenko G.P. Resurgence of diphtheria. Eur. J. Epidem. 1995; 11:95-105.

3. Hardy, I.R.B., Dittmann, S., and Sutter, R. Current situation and control strategies for resurgence of diphtheria in Newly Independent States of the former Soviet Union. Lancet. 1996; 347:739-43.

4. Dittmann, S. Epidemic diphtheria in the Newly Independent States of the former Soviet USSR-situation and lessons learned. Biologicals. 1997; 25:179-186.

5. Dittmann, S., and Raure, C. Diphtheria. Plan of Action for the Prevention and Control of Diphtheria in the European Region (1994-1995). The Expanded Programme on Immunization in the European Region of WHO, ICP EPI 038 (A). Copenhagen: WHO 1994.

6. WHO Expanded Programme on immunization weekly. Epidemiol. Rec. 1984; 39:297-300.

7. Rothenberg, R.B., Labanav, A., Sing, K.B. and Strah, Jr. G. Observations on the applications of EPI cluster survey methods for estimating disease incidence. Bull. WHO. 1985; 63:93-99.

8. Henderson, R.H. and Sunderason, T. Cluster sampling to assess immunization coverage: a review of experience with a simplified sampling method. Bull WHO. 1982; 60:20532060.

9. Cohen, L. and Holliday M. eds. Statistics for Social Scientist: London, 1983: 69-75.

10. Meluille-Smith, M. and Balfour A. Estimation of Corynebacteriumdiphtheriae antitoxin in human: a comparison of an enzyme-linked immunosorbent assay with the toxin neutrolisation test. J. Med. Microbiol. 1988; 25:279-283.

11. Galazka, A. and Keja, J. Diphtheria: Incidence trends and age-wise changes in immunity. Scand. J. Inf. Dis. 1988; 20:355-356.

12. Begg, N. and Balraj, V. Diphtheria: are we ready for it? Arch. Dis. Child. 1995; 73:568-572.

13. Vitec, C.R. and Warton, M. Diphtheria in the former Soviet 
Union: re-emergence of a pandemic disease. Emer Inf Dis. 1998; 4:539-549.

14. Turkish Medical Association. Health Statistics of Turkey. Ankara. 2000; 42

15. Galazka, A.M., Diphtheria. The immunological basis for immunization. WHO document. WHO/EPI/GEN/93. 1 2.Geneva, 1993.

16. Galazka, A.M. General immunology: The immunological basis for immunization. WHO document. WHO/EPI/GEN/ 93.11. Geneva, 1993.

17. Tumay, S.F. Vaccination status against diphtheria of the studied children at 0-9 age group and immunity against diphtheria of the studied population of all age group in Istanbul. Gazi University Faculty of Medicine, Department of Public Health. Ankara. 1999.

18. Christenson, B. and Bottiger, M. Serological immunity to diphtheria in Sweden in 1978 and 1984. Scand. J. Infect. Dis. 1986; 18:227-233.
19. Hunolstein, C., Rota, M.C., Alfarone, G., Ricci, M.L. and Salmaso, S. Diphtheria antibody levels in the Italian population. Eur. J. Clin. Microbiol. Infect. Dis. 2000; 19:433-437.

20. Ronne, T., Valentelis, R., Tarum, S. et al. Immune response to diphtheria booster vaccine in the Baltic States. J. Inf. Dis. 2000; 181:213-219.

21. CDC. MMWR. Surveillance for Vaccination Coverage Among Children and Adults-United States. Sept. 2000; 49 (SS-9):816.

22. Forsell, P. Diphtheria, Immunity in Victoria. Med. J. Aust. 1972; 1:1023-1026.

23. Williams, I.T., Milton, J.D., Farrell, J.B. and Graham, N.M. Interaction of socioeconomic status and provider practices as predictors of immunization coverage in Virginia children. Paediatrics. 1995; 96:439-446.

24. The Hacettepe Institute of Population Studies. Turkish Demographic and Health Survey Report 1998. Ankara. 1999:114-16. 